\title{
Approaches to setting forestry research priorities: Considering the benefits of reducing uncertainty
}

\author{
by G. Nilsson ${ }^{1}$, M.K. Luckert² ${ }^{2}$ G.W. Armstrong ${ }^{3}$, G.K. Hauer ${ }^{4}$ and M.J. Messmer ${ }^{5}$
}

This paper reviews current approaches to research topic selection in forest management. Most current approaches are based on soliciting expert opinion of researchers within an environment where research demands may enter through media and political events. A number of potential problems are identified with these types of approaches including: research issues changing too rapidly for research programs to adapt, inability of surveys to capture long term trends in priorities, potential for processes to be captured by special interests of particular stakeholders, potential for consensus seeking to lead to research priorities that are too broad, a lack of statistical differences between topics leading to no significant priorities, a lack of explicit linking of the supply and demand for forestry research, and the potential for media to misrepresent research demands. Building on this literature, we suggest that current research selection methods be supplemented by developing new frameworks to provide more explicit information for research topic selection in forest management that would reduce the current pervasive role of subjectivity, provide research guidelines for local regions, and incorporate quantitative methods. This framework could be based upon the idea that one value of information is the reduction of costly mistakes. We suggest that sensitivity analyses on savings from potentially reduced uncertainty, within the context of different institutional constraints, could provide explicit information to assist with research topic selection.

Key words: forestry research priorities, returns to research, value of information

Cet article révise les approches actuelles de sélection des sujets de recherche en aménagement forestier. La plupart des approches courantes reposent sur la sollicitation d'avis d'expert auprès des chercheurs issus d'un environnement où les demandes de recherche peuvent être générées par les médias et les événements politiques. Certains problèmes potentiels sont identifiés pour ces types d'approche dont la modification trop rapide des sujets de recherche ne permettant pas aux programmes de recherche de s'adapter, l'incapacité des sondages de saisir les tendances à long terme parmi les priorités, la possibilité que les processus soient centrés sur des intérêts privilégiés par certains intervenants, la possibilité que la recherche de consensus mène à entreprendre des priorités de recherche trop générales, une absence de différence statistique entre les sujets engendrant aucune priorité significative, une absence de relation explicite entre l'offre et la demande en matière de recherche forestière et la possibilité que les médias interprètent mal les demandes de recherche. En fonction de ces constatations, nous suggérons que les méthodes actuelles de sélection des recherches soient renforcées par l'élaboration d'un nouveau cadre de référence qui apportera plus d'information explicite pour la sélection de sujets de recherche en aménagement forestier et qui permettrait de réduire l'omniprésence de la subjectivité, de fournir des lignes directrices pour les régions et d'incorporer des méthodes quantitatives. Ce cadre de référence pourrait reposer sur le concept que la valeur de l'information réside dans la réduction des erreurs coûteuses. Nous suggérons que les analyses de sensibilité sur les économies tirées de la réduction potentielle de l'incertitude, en fonction du contexte des différentes contraintes institutionnelles, pourraient apporter de l'information explicite pour la sélection de sujets de recherche.

Mots-clés: priorités de recherche forestière, retombées de la recherche, valeur de l'information

\section{Introduction}

The potential importance of research to the future of forestry in Canada has been a pervasive issue over the last decades. Research has the potential to fuel technological change by introducing more productive forest management practices. Accordingly, a number of authors have considered economic costs and benefits of research (e.g., McKenney et al. 1988, 1994; Hyde et al. 1989, Davis et al. 1994). Despite the recognized benefits from forestry research, others have shown how Canada tends to lag behind many of its global trade competitors in research spending (e.g., Binkley and Watts 1992, Binkley 1995, Binkley and Forgacs 1997).

It may be argued that it is not the amount of research dollars that are spent that is important, but how wisely those dollars are spent. Along these lines, a number of authors have pointed out problems in the way research dollars are allocated. For exam-

${ }^{1}$ Forest Analyst, The Forestry Corp.

${ }^{2}$ Professor, Department of Rural Economy, University of Alberta, Edmonton, AB T6G 3S5. E-mail: marty.luckert@ualberta.ca (corresponding author).

${ }^{3}$ Assistant Professor, Department of Renewable Resources, University of Alberta.

${ }^{4}$ Assistant Professor, Department of Rural Economy, University of Alberta.

${ }^{5}$ Forest Economist, Victoria, British Columbia. ple, Friedman (2000) identified "(armies) of proposal writers..., piecemeal attempts to solve problems, scientists addressing problems that do not exist and not addressing ones that do, and managers shooting in the dark while making decisions" as some of the causes of inefficient spending on research. Martell (1992) has also criticized forestry research, and emphasized a requirement for researchers to directly address practical forestry problems. He added that comprehensive research programs should not only generate new knowledge, but should also help forest managers use new knowledge, otherwise we will continue to "...overwhelm forest managers with growing amounts of seemingly meaningless data that are of little or no practical value."

The above critiques indicate that research must serve the needs of a number of groups. Research in forestry is sometimes for practitioners who demand new knowledge in forestry, be they industrial or government forest managers or policy-makers ${ }^{5}$. Forestry research may also focus on areas where the general public has concerns. Along these lines, Andersson et al. (2000) pointed to a need to pursue forest policy and research in a context where the needs of society, the public and the forest owners meet. The

\footnotetext{
${ }^{5}$ This statement is not meant to imply that applied research is more valuable than basic research. Basic research may often be linked to improvements in social welfare. However, the direct relevance of basic research may be harder to establish, a priori, than with applied research.
} 
multiplicity of values that forests must supply for all of these stakeholders in the context of sustainable forest management creates endless research possibilities.

In the context of so many competing demands for research, it can be difficult to prioritize research efforts. To this end, a number of methods for selecting research priorities within forestry have been developed. One purpose of this paper is to explore current research selection systems in forest management and to identify potential problems with current systems. In reviewing these systems, it becomes clear that a common problem lies in difficulties in identifying costs and benefits of research to society from alternative research priorities. Methods have been developed which, at regional and/or international levels, estimate the economic impacts of forestry research, while considering costs and benefits of alternative research priorities (e.g., Davis et al. 1994). However, our focus here is a more micro-level approach. Looking at the issue of research from the view of practising foresters and local forest users, an important value of new information arises from potentially reducing costly mistakes due to uncertainty.

In the forestry sector, there are numerous sources of uncertainty in planning and decision-making. Knowledge of biological patterns, processes and responses to forest management are limited (Pearse 1990). The impacts of fire, insects, and other natural disturbance contribute to uncertainty. Also, political constraints, policy specifications and future technological innovations can be unclear (Marshall 1987). These uncertainties, and others, are compounded by the long-term planning horizon found in a variety of plans used by forest sector planners.

Reducing uncertainty can be a major benefit of research. If costly mistakes can be avoided, costly research may be easier to justify. However, given the pervasiveness of uncertainty, and limited research funding, choices must be made regarding the types of research to fund. Therefore, a second purpose of this paper is to suggest how benefits of reducing uncertainty can be used to influence research prioritization decisions.

The paper begins with a critical review of current approaches to forestry research topic selection that exist in Canada and the United States. This leads to a review of literature that addresses dealing with uncertainty in forest management, and the potential role that research can play in reducing that uncertainty. We suggest that sensitivity analyses on the effects of current and potentially reduced uncertainty could provide explicit information to assist with research topic selection.

\section{Examples of Current Approaches of Selecting Forestry Research Topics}

A number of different means have been used to prioritize research topics in forestry. Many of these methods have relied on attempting to collect the expert opinion of selected groups. These opinions are likely to be influenced by the specific expertise and interests of the people being surveyed. The respondent's ideas may also be influenced by the media and other social events that have a bearing on forests. Below, we provide examples of expert selection systems and extrinsic influences that may affect the selection process. As part of this review, we consider criticisms that have been raised regarding the different means of prioritizing forestry research.

\section{Expert opinion methods}

Forestry Research Advisory Council of Canada

The Forestry Research Advisory Council of Canada (FRACC) prepared annual overviews of forest research priorities across
Canada for the Canadian Council of Forest Ministers (CCFM) between 1989 and $1995^{6}$. The overviews were based on solicited input from provincial and territorial forest research bodies who were asked in a survey to list their top five priorities for forest research. Two of these surveys are discussed here-one conducted in 1991 and the other in 1993. In the 1991 survey, advisory groups across the country responded to the Council's following survey questions (FRACC 1992) ${ }^{7}$ :

1. Name the five top forest research priorities for work needed to ensure a sustainable flow of all forest benefits.

2. Of the five topics named, identify those that are adequately funded and supported.

3. Identify those that are not adequately funded and supported.

4. If possible, suggest how to fund work that is not adequately funded.

5. Describe emerging issues that are likely to affect future forest research priorities.

6. Comment on the adequacy of forest research in your area. Table 1 lists the priorities that were identified and ranked (1 through 10, highest to lowest) in both the 1991 and 1993 surveys. The authors (FRACC 1994) compared the 1991 and 1993 priorities and discovered some marked changes. Indeed, the top priority identified in 1991, Environmental Effects of Forest Management, was not even mentioned as a priority in 1993. Furthermore, in the 1991 survey results, Alberta respondents noted that their "top five priorities are inadequately supported, but that the program is well rounded, with a balance of basic, applied, environmental and forest management research" (FRACC 1992). In the 1993 survey, however, Alberta respondents described forestry research as "polarized, not well coordinated with industry, [lacking] long-term strategy, shortterm oriented, [lacking] well-defined scientific and operational values, [and lacking] accepted uniform project evaluation" (FRACC 1994).

One potential consequence of these differing results is that priorities may be changing at rates that research programs cannot adjust to quickly enough (FRACC 1992). However, the authors changed their tune in 1994 stating that research priorities are "...not changing too quickly for research agencies to adapt." Regardless of whether research programs are able to adapt rapidly or not, marked and rapid changes in priorities over time may reveal possible limitations in this process of selecting priorities and research programs. Do opinions regarding research priorities and programs really change to such a degree over a twoyear period, or is the survey overly sensitive and simply not capturing long-term trends in opinions? The answers to both parts of this question are likely yes, given the rate at which public preferences seem to be changing, and the open-ended survey structures that were used.

\section{The Alberta Research Council}

The Alberta Research Council (ARC) is a provincial science and research organization that performs applied research and development in the areas of agriculture, energy, environment, forestry, health and manufacturing industries (K. Greenway,

\footnotetext{
${ }^{6}$ The FRACC is no longer in existence; the Science and Technology Working Group is a CCFM initiative that now fulfills a similar role to FRACC (CCFM 1998).

${ }^{7}$ The 1993 survey was similar to the one in 1991.
} 


\begin{tabular}{lll}
\hline \multicolumn{2}{l}{ Table 1. Comparison of identified research priorities (FRACC 1992, 1994) } \\
\hline Priority rating & \multicolumn{1}{c}{$\mathbf{1 9 9 1}$} & \multicolumn{1}{c}{$\mathbf{1 9 9 3}$} \\
\hline 1 & Environmental effects of forest management & \\
& & $\begin{array}{l}\text { Integrated forest landscape management systems and decision } \\
\text { support }\end{array}$ \\
2 & Pest and weed management and alternatives to chemicals & Inventory, growth and yield, ecological site classification \\
3 & Decision support for management, silviculture and land use & Ecosystem functioning, soil and biodiversity conservation \\
4 & Ecological knowledge for intensive forest management & Pest and weed management and alternatives to chemicals \\
5 & Integrated resource management systems & Ecological effects of natural and human-caused distu bances \\
6 & Site-productivity classification systems & Lower-cost silviculture and harvesting, natural regeneration \\
7 & Growth and yield data for managed and unmanaged stands & Forest fire management and control \\
8 & Silvicultural and harvesting methods and cost reduction & Socio-economic knowledge and resolution of resource use \\
& & conflicts \\
9 & Forest fire management and control & Mixedwood management \\
10 & Tree improvement and genetics & Incentives for private investment \\
\hline
\end{tabular}

personal communication, March 15, 2000). The ARC hosted a series of mixedwood workshops in 1998 and in 2000 to identify forestry research priorities regarding mixedwood management. Workshop members held brainstorming sessions to identify areas where they felt further mixedwood research was needed and subsequently ranked each issue in order of importance (K. Greenway, personal communication, March 15, 2000). In the 2000 workshop, participants identified the following topics as research priorities:

1. Predict natural and treatment successional pathways

2. Modeling mixedwood succession with respect to yield curves

3. Review of silviculture research

4. Economic analysis of treatment options

5. Site capability of different species on a site

6. Critical intervention points

Ideally, consultation processes such as this one result in mutually acceptable decisions. However, the process may “...leave decision-making more open to practices of bargaining, negotiation and coercion, which undermine claims that consensus has been achieved in a particular situation" (Richardson and Connelly 2002). Like many decision-making processes, each person's opinion has the potential to be influenced by the group and, as a result, the group can potentially bias the results of the workshop. Furthermore, consensus may be achieved at the cost of creating a document with broad and vague guidelines, which may be of little use for providing guidance to specific research projects.

\section{Northeast Forest Resources Extension Council}

Broderick et al. (1991) reviewed a research topic selection survey by the Northeast Forest Resources Extension Council (NEFREC). NEFREC is a council created in 1983 to identify, prioritize and design educational programs to address emerging renewable resource issues of regional importance. In 1986, the NEFREC conducted a survey to petition opinions on research priorities from foresters in the northeastern United States. The open-ended questionnaire contained 13 category headings and respondents were asked to list, under the appropriate heading, problems or questions they felt needed to be addressed by research. Those research topics that were listed five or more times by individual respondents were used as a platform. This platform was used to create a more specific list of potential research topics, categorized under 11 subject headings. In 1989, an additional survey was conducted based on this list, and respondents were asked to rate each topic according to whether it required further research. Respondents in 1989 were asked to also give their opinions on how they would allocate research bud- gets among the 11 major subject headings. The results of the 1989 survey revealed the following forest research priorities:

1. Forest decline

2. Economics and marketing

3. Regeneration

4. Silviculture

5. Insect and disease problems

6. Harvesting technology

The authors noted a tremendous diversity of opinion in the survey. "Every potential research topic on the questionnaire was rated as being an 'extremely high need' by some and 'not needed' by others" (Broderick et al. 1991). In addition, "t-tests revealed no statistically significant difference $(\mathrm{p}=0.05)$ between any two adjacent topics on the ranked list" (Broderick et al. 1991). This insignificance brings into question the value of having a prioritized list of research topics.

\section{MAPLE Scoring Model}

The MAPLE scoring model was adapted from Australia's Commonwealth Scientific and Industrial Research Organization by Simkus et al. (1996) to assist in setting forest research priorities in Canada. Given a set of research proposals, the process involves leading users through a framework of questions to produce a score for each project. The model is based on four criteria: research potential rating, research capacity, potential benefits and the ability to capture benefits. The research potential and research capacity criteria refer to the size of the initiative and the anticipated usefulness of research results from the proposed project. The benefits and ability to capture benefits criteria refer to expected "net economic, environmental, and social advantages which may be realized in Canada as a direct result of the project." A separate worksheet for each of the four criteria provides decision-makers with a set of questions. The questions are answered by rating the project relative to other projects under consideration; these ratings are converted to a project score. Decision-makers then use these scores within the MAPLE spreadsheet framework to help create a research portfolio.

Similar to previous methods, the MAPLE Scoring System solicits input from experts to rank research priorities. However, it differs by providing an explicit framework within which the expert opinions can be organized. Specifically, it requires respondents to think about usefulness of research results. However, since the MAPLE model prioritizes topics from an existing group of research proposals, it provides no means to develop an initial list of priorities from which researchers could select topics. The process is supply-side driven, and may not adequately consider research demands. 


\section{Extrinsic factors}

Given that many of the respondents surveyed for prioritizing forestry research are researchers, it is reasonable to suspect that these research priorities represent, fairly well, the researcher's capabilities and interests. Ideally, research funding would respond explicitly to a social demand for research. One way that such social demands may enter is by influencing the broader social environment within which research is conducted.

For example, elections and consequent political rotations that occur every three to five years, as well as the impact of national and international agreements, can considerably influence the direction of forestry research by influencing researchers and funding agencies' perceptions of what is important. Along these lines, the Kyoto Protocol of 1997 sets targets for the reduction of greenhouse gas emissions. One consequence of these targets is a need for research on "problems associated with the mechanism to transfer land out of agriculture into plantation forest," since the practice of afforestation on marginal agricultural land can increase terrestrial carbon uptake (van Kooten et al. 1999). As another example, the Montreal Process developed a set of criteria and indicators that can be used to measure the sustainability of forest management. The first of the six criteria is the Conservation of Biological Diversity (CCFM 2000), and this criterion alone has influenced the direction of forestry research. For instance, the CCFM (2000) suggests:

“...with adequate management and research strategies, Canada should be able to maintain its forest biodiversity for future generations. However, more knowledge is required of all three forest biodiversity elementsecosystems, species and genes."

However, some of the information about these extrinsic factors is delivered through various news media which may filter the messages. News media can influence the selection of forestry research topics when it brings certain aspects of forest science and environmental issues into the limelight. In turn, members of the public can pressure governments and businesses to invoke change in perceived significant issues. Without belittling the role of public opinion in forest management decisions, it is important to realize the potential for miscommunication between researchers, the media and the public. Powell and Leiss (1997) examine case studies of communication between the science, the media and the public, in the book, Mad Cows and Mother's Milk. They suggest that although many members of the public look mostly to the media for scientific information, the media often misrepresent, partially or wholly, environmental issues and risks. Marshall (1987) also suggests "frequently the public is not well informed and lacks the necessary training to understand the biological and economic processes of the forest."

There are various suggested reasons for the potential misrepresentation of scientific information in the media. Lichter et al. (2000) conclude that,

“...the difficulty of providing an accurate recounting of reality is exaggerated for science journalism, due to the complexity of the subject matter and the lack of knowledge among the news audience. Yet policy makers and the general population alike rely on accurate reporting of scientific controversy and consensus to help them plan, carry on, and make sense of their daily lives."

\section{Discussion of current approaches}

Current research selection systems rely heavily on subjective input and/or consensus building. These methods may provide valuable information regarding research priorities; however, the preceding discussion reveals several insights into how the efficiency of these systems might be improved.

Subjectivity is very prevalent in current research selection systems. Surveys and workshops are often used to solicit opinions from field experts on research priorities. To the degree that these methods will reflect current concerns about forest practices, either from experts, members of the public, or from international agreements, they are potentially valuable approaches. However, paradigms and attitudes are in a constant state of change and will inherently affect year-to-year research priorities. Inefficiency, then, arises if research agencies are unable to keep up with changing research priorities.

Consensus-building is a commonly used tool in research priorities selection. Ideally, consensus results in mutually agreed upon decisions. In the development of a consensus, it is almost certain that individual choices will be influenced or manipulated by the group. Furthermore, as past studies have shown, using consensus building to identify research priorities can result in overly broad and vague guidelines. In one sense, priorities developed for a national scale must be fairly broad in order to remain applicable across local regions and to prevent guidelines that are too prescriptive and inhibit the generation of good research (R. Taylor, Science Advisor, Science Branch, Canadian Forest Service, personal communication, November 28, 2000). However, there may be a need for additional research selection guidelines that would provide more specific direction for local regions.

The variability in priorities that may arise from current research prioritizing methods is also troublesome. Variability may be so great that agreement necessary for prioritization may be impossible. Given the potentially vast range of greatly differing opinions about what is important, it is not clear that current methods identify those issues that are most important over time.

Perhaps a more focused system that gathers quantitative information to aid research topic selection would address practical forestry problems, help managers use new knowledge, and streamline research programs. Furthermore, the overwhelming reliance on qualitative input apparent in current research selection systems emphasizes the lack of quantitative analysis that goes into the selection processes. Although subjectivity can by no means be eliminated, since it is an inevitable element of any human-related activity ${ }^{8}$, the addition of more quantitative methods could perhaps complement current systems.

Lastly, as an information source, the media may influence the allocation of effort in forestry research topics by their choice of focus on a variety of environmental issues. While we do not suggest altering the role of the public in selecting

\footnotetext{
${ }^{8}$ This proposition was discussed as early as 1844 when Karl Marx wrote that man is a "subjective existence of thought" (Marx 1844). Matthews (1998) also addressed the use of subjectivity in scientific research. Recognizing that the scientific community tends to regard objectivity as the key that distinguishes "genuine science from pseudo-science", Matthews used arguments and case studies to prove the prevalence and necessity of subjectivity in research. In one such example he asked, "what objective principle underpins the choice of $\alpha$, the cut-off level for 'significance'..."
} 
research priorities, it may be beneficial to attempt to link public demands with the supply capabilities of researchers in a more explicit fashion. That is, it may be beneficial to consider demand side benefits of research in relation to supply side capabilities and costs.

In summary, a framework to provide more information for research topic selection could aim to reduce the pervasive role of subjectivity, provide guidelines for local regions, incorporate quantitative methods, and consider demand and supplyside aspects of forestry research. Looking at the issue of research from the view of a practising forester, an important value of new information arises from potentially reducing costly mistakes due to uncertainty. As such, research topic selection and data collection could be driven, in part, by the benefits of reduced uncertainty relative to the costs of gathering information. Having made this suggestion, it is helpful to explore literature that addresses uncertainty in forest management planning.

\section{Uncertainty in Forest Management Planning}

Uncertainty seems to be omnipresent in attempting to manage for the multiple objectives of sustainable forest management. In the examples that follow, we focus on one aspect of uncertainty - that relating to timber supply. This focus is not meant to diminish the importance of other non-timber objectives. Rather, it is meant to provide a concrete, focused example regarding how uncertainty may be linked to research priorities.

Uncertainty may be assessed at different levels of complexity. An initial level is to explore existing levels of uncertainty with means such as sensitivity analysis. If it is decided that decisions are sensitive to uncertainty, a next step may be investigating means of reducing uncertainty. Yet a further level of analysis may attempt to assess how beneficial reducing uncertainty is so that it might be considered relative to costs. Finally, there may be features of institutional environments, such as forest tenures, that influence who bears the costs of research and who receives the benefits of reduced uncertainty. The review below takes us through examples of each of these four steps.

\section{Exploring existing uncertainty}

The British Columbia (BC) Forest Service completes timber supply area analysis reports at least once every five years for each timber supply area in BC. The reports examine the shortand long-term effects of current forest management practices and variable parameter estimates on timber supply. The North Coast timber supply area analysis report (BC Forest Service 1999) states that managers cannot be certain that all data accurately reflect the current state of all values in the forest, how the forest will change, or how management activities will affect the forest. To address this uncertainty, sensitivity analyses are used to examine how measured criteria change when inaccurate planning parameters are used. One such sensitivity analysis, in the 1999 report, looked at the effects of variation in timber supply volume estimates on allowable annual cut (AAC). Standing timber volume estimates are subject to uncertainty because they are based on extrapolation and on inventory classifications that contain some uncertainty; there is also uncertainty in decay estimates, waste estimates, and breakage during harvest. The report found that a change in current volume estimates by $10 \%$ in either direction considerably disrupted harvest levels.

The BC analyses used inventory data to examine the implications of uncertainty on some important parameters; however, such data are not necessarily available for all parameters. Van Kooten et al (1992) demonstrated a method to incorporate uncertain growth rates into forest management models in instances where empirical estimates of uncertain parameters do not exist. Such instances are seen both in managed stands, for which the effects of management are uncertain, and unmanaged stands, for which age-volume tables, for example, "do not provide information about the variance of stand growth." They suggested soliciting expert opinions of parameter uncertainty from tree physiologists and other foresters. This would involve asking qualified experts to describe the most likely, the maximum, and the minimum outcomes of different management regimes on growth rates, utilizing graphical comparisons of various growth functions. These estimates could be used to create triangular probability density distributions around the parameters. The authors proceeded to examine the effects of uncertain growth rates on timber supply projections. They found that rotation length decreased as a function of uncertainty in both deterministic and stochastic models, and that flexible harvest policies were preferable in the presence of uncertainty. They suggested that there could be significant savings to society and the private sector when uncertainty is considered in forest planning.

\section{Reducing uncertainty}

Uncertainty in planning parameters may be reduced by increasing research efforts, or by improving inventory data through increased sampling or stratification. Wang and Huang (2000) found that increased stratification could reduce the uncertainty around timber volume estimates for Alberta's wetland mixedwood (WMX) natural subregion. They developed "...height and site-index models for each (of Alberta's five, sic) natural subregions... and compared these models to the provincial model developed by Huang (1994)." Only the WMX subregion had height-age curves different from the provincial models.

“...large errors in volume estimation occurred when the provincial height and site index model was applied to the WMX natural subregion. At age $<50$ years, volumes were underestimated by up to $25 \%$. The under-estimation increased with site index. At age $>50$ years, volumes were underestimated (by up to $19 \%$ ) for stands with low site indices, but were overestimated (by up to 20\%) for stands with high site indices. These over- and underestimates increased with age."

Given that the heights of even-aged stands have been commonly used "as a measure of forest productivity and a "driving' variable in many growth and yield models," results such as these may generate benefits by measurably reducing uncertainty in timber supply modeling (Wang and Huang 2000). ${ }^{9}$

\section{Estimating benefits of uncertainty reduction}

If uncertainty is to be reduced, a next logical step is to consider the benefits and costs of doing so. Along these lines, Eid (2000) recognized that little attention is given to uncertainty in

\footnotetext{
${ }^{9}$ In some respects, this is what has happened with site productivity ratings in Alberta. Under Phase III timber productivity ratings, most areas were grouped into medium productivity classes. With the addition of ecosite-based productivity estimates, the distribution has changed with greater representation in good and poor classes. Also, the average value of site index by class has shifted upward.
} 
forest inventory data nor to the effect of that uncertainty on longterm timber production analyses, and presented a way to incorporate uncertainty into Norwegian forest planning. Eid found that inventorying efforts were being misplaced, such that efforts to reduce uncertainty were being directed towards parameters that did not significantly influence production values of timber supply. He introduced the use of "... decision-oriented inventory planning" whereby the planning process incorporates the uncertainty that is associated with using erroneous data. Then, he expressed the monetary value of inventory information in its ability to increase the value of timber supplies.

\section{Impacts of institutions on flows of benefits from reduc- ing uncertainty}

Forest management research and information collection to reduce uncertainty can generate benefits to multiple parties, from the landowner (e.g., the Crown) and forest companies, to forest product consumers and society. The perspective from which benefits are being measured or estimated is important since values are different to different parties.

The amount and distribution of benefits depends on current policies, economic conditions and the political environment. The flow of benefits from a forest can be affected by institutional constraints (Center for International Forestry Research 1999):

\begin{abstract}
"...the royalty, fee or tax or market regime can have a significant effect on how much resource value is generated, and how much of it accrues to an owner. The manager, who may be responsible for any or all of logging, replanting, processing or marketing of the products, will typically enjoy a share of the rent or perhaps a subsidy. Domestic consumers may also share in the rents through consumption subsidies. Rent shares to consumers are typically low, except in instances where entire forest stands have been turned over to communities to manage. Finally, local individuals or communities may be compensated through direct or transfer payments."
\end{abstract}

Following these explanations, it is important to consider benefits from reducing uncertainty within policy constraints. Accordingly, Nilsson (2003) investigated how benefits of reducing uncertainty may be influenced by allowable annual cuts (AACs). Benefits of reducing uncertainty were found to be greater when AAC constraints were less stringent, because supply crashes (i.e., non-sustainable harvest levels) could be more easily averted with less stringent harvesting constraints.

\section{Discussion on reducing uncertainty}

The above studies dealing with uncertainty introduce a fundamental concept that could be used to help select research topics to analyze the effects of variable parameter estimates. Building on those methods, sensitivity analyses on the effects of current and potentially reduced uncertainty could provide explicit information to assist with research topic selection, and might improve the current, rather ad hoc, use of subjective input. Establishing a link between the sensitivity analyses and research topic selection may reduce the gap in information transfer from the research community to practicing foresters, as discussed by Broderick et al. (1991). Overall, the link would essentially examine the benefits of adaptive forest management, a paradigm that has recently gained importance in international forest management circles (e.g., Walters 1986).
Since the benefits of uncertainty reduction may, to some extent, follow the distribution of benefits from forests, the value of research could be examined from the perspectives of different beneficiaries-namely, the private versus public sectors. Uncertainty reduction may affect benefits as they are seen within policy constraints and, therefore, it may be useful to examine how benefits may be affected by different institutional constraints.

\section{Summary and Conclusions}

Ideally, research should bridge gaps between researchers, practitioners and society at large. This ideal is not always met with current methods of selecting research priorities. This paper reviews current approaches to research topic selection in forest management. Most current approaches are based on soliciting expert opinion of researchers within an environment where research demands may enter through media and political events. A number of potential problems are identified with these types of approaches including: research issues changing too rapidly for research programs to adapt, inability of surveys to capture long term trends in priorities, potential for processes to be captured by special interests of specific stakeholders, potential for consensus seeking to lead to research priorities that are too broad, a lack of statistical differences between topics leading to no significant priorities, a lack of explicit linking of the supply and demand for forestry research, and the potential for media to misrepresent research demands.

Building on this literature, we suggest that current research selection methods be supplemented by developing new frameworks to provide more explicit information for research topic selection in forest management that would reduce the current pervasive role of subjectivity, provide research guidelines for local regions, and incorporate quantitative methods. This framework could be based upon the idea that one value of information results from reducing costly mistakes. Therefore, research topic selection and data collection could be driven, in part, by the benefits of reduced uncertainty relative to the costs of the gathering information.

Drawing from existing literature that addresses uncertainty in forest management, we suggest that sensitivity analyses on the effects of current and potentially reduced uncertainty could provide explicit information to assist with research topic selection. These sensitivity analyses could consider how the benefits of reducing uncertainty in forest management may be affected by different institutional constraints.

\section{Acknowledgements}

Thanks to two anonymous reviewers, and an Associate Editor for their helpful comments. Also, thanks to the Sustainable Forest Management Network for providing research funding.

\section{References}

Andersson, F.O., K.H. Feger, R.F. Hüttl, N. Kräuchi, L. Mattson, O. Sallnäs and K. Sjöberg. 2000. Forest ecosystem research - priorities for Europe. Forest Ecology and Management 132: 111-119. Binkley, C.S. 1995. Designing an effective forest sector research strategy for Canada. The Forestry Chronicle 71(5): 589-595.

Binkley, C.S. and O.L. Forgacs. 1997. Status of Forest Sector Research and Development in Canada. http://forcast.forest.ca/pdf/ binkrp_e.pdf (Accessed 2003 Feb 10).

Binkley, Clark S. and S.B. Watts. 1992. The status of forestry research in British Columbia. The Forestry Chronicle 68(6): 730-735. British Columbia Forest Service. 1999. North Coast Timber Supply Area Analysis Report, November 1999. http://www.for.gov.bc.ca/ tsb/tsr2/tsa/tsa26/report/httoc.htm (Accessed 2000 Nov 17). 
Broderick, S.H., D.B. Kittredge, D.J. Decker and N.A Connelly. 1991. Practicing foresters identify research needs: Northeastern survey locates gaps in information flow. Journal of Forestry August: 27-35. Canadian Council of Forest Ministers (CCFM). 1998. Home Page. http://www.ccfm.org/home_e.html (Accessed 2000 Dec 3). Canadian Council of Forest Ministers (CCFM). 2000. Criteria and Indicators of Sustainable Forest Management in Canada. http://www.nrcan.gc.ca/cfs/proj/ppiab/ci/indica_e.html (Accessed 2000 Dec 3).

Centre for International Forestry Research. 1999. Indicator L1. Mechanisms exist for sharing the economic benefits derived from forest management. http://www.fs.fed.us/institute/cifor/cifor_234.html (Accessed 2002 July 5).

Davis, J.S., D.W. McKenney and J.W. Turnbull. 1994. The international impact of forestry research and a comparison with agricultural and fisheries research. Canadian Journal of Forest Research. 24: 321-336.

Eid, T. 2000. Use of uncertain inventory data in forestry scenario models and consequential incorrect harvest decisions. Silva Fennica 34(2): 89-100.

Forestry Research Advisory Committee of Canada (FRACC). 1992 Forest research priorities in Canada, 1991: An overview for the Canadian Council of Forest Ministers. Forestry Chronicle 68: 121-125.

Forestry Research Advisory Committee of Canada (FRACC). 1994. Forest research priorities in Canada, 1993: An overview for the Canadian Council of Forest Ministers. Forestry Chronicle 70: 84-87. Friedman, S. 2000. Twenty suggestions for improving the use of science in forest management. http://info.metla.fi/iufro95abs/d6pap16.htm (Accessed 2000 Nov 17).

Huang, S., 1994. Ecologically based reference-age invariant polymorphic height growth and site index curves for white spruce in Alberta. Land and Forest Service, Alberta Environmental Protection, Edmonton, Alberta. Tech. Rep. Pub. No. T/305.

Hyde, W.F., D.H. Newman and B.J. Seldon. 1989. The Benefits of Forestry Research. Forest Economics and Policy Analysis Research. Working Paper 134.

Lichter, S.R., D. Amundson and L.S. Lichter. 2000. Media Coverage of Global Warming 1985-1991. http://www.cmpa.com/archive/ warm.htm (Accessed 2000 Dec 3).

Marshall, P.L. 1987. Sources of uncertainty in timber supply projections. The Forestry Chronicle. 63(3): 165-168.

Martell, D.L. 1992. Forestry research implementation. The Forestry Chronicle 68(3): 355-356.
Marx, K. 1844. The Economic and Philosophical Manuscripts; Third Manuscript: Private Property and Labor. http://csf.colorado.edu/psn/marx/Archive/1844-EPM/ (Accessed 2001 May 14). Matthews, R.A.J. 1998. Facts versus Factions: The Use and abuse of subjectivity in scientific research. http://ourworld.compuserve.com/ homepages/rajm/openesef.htm (Accessed 2001 May 14.)

McKenney, D.W., J.S. Davis and K.L. Campbell. 1994. Towards an Information System to Support Forestry Research Priority Setting: Some Preliminary Results for Canada. Great Lakes Forestry Center, Canadian Forest Service. Ontario. 19 p.

McKenney, D., W. van Vuuren and G. Fox. 1988. The Economics of Tree Improvement: A Comparison of Clonal Forestry and Seed Orchards for Black Spruce in Ontario. University of Guelph, Ontario. 61 p.

Nilsson, G. 2003. Using Cost Assessments of Planning Uncertainties to Direct Forest Management Information Collection. M.Sc. Thesis, Department of Rural Economy, University of Alberta, Edmonton. 106 p.

Pearse, P.H. 1990. Forestry Economics. University of British Columbia Press, Vancouver, BC. 226 p.

Powell, D. and W. Leiss. 1997. Mad Cows and Mother's Milk. McGill Queen's University Press, Quebec City, Quebec. 308 p.

Richardson, T. and S. Connelly. 2002. Building consensus for rural development and planning in Scotland: A Review of best practice. http://www.scotland.gov.uk/cru/kd01/orange/bcrd.pdf (Accessed 2003 Feb 5.)

Simkus, G., G. Fox and D. McKenney. 1996. MAPLE: A Scoring model for forest research priority setting. Northern Ontario Development Agreement. Great Lakes Forestry Center, Natural Resources Canada, Ottawa. 7 p.

van Kooten, G.C., R.E. van Kooten and G.L. Brown. 1992. Modeling the effect of uncertainty on timber harvest: A Suggested approach and empirical example. Journal of Agricultural and Resource Economics. 17(1): 162-172.

van Kooten, G.C., E. Krcmar-Nozic, B. Stennes and R. Van-Gorkom. 1999. Economics of fossil fuel substitution and wood product sinks when trees are planted to sequester carbon on agricultural lands in western Canada. Canadian Journal of Forest Research. 29(11): 1669-1678. Wang, G.G. and S. Huang. 2000. Height growth pattern of white spruce in natural subregions in Alberta, Canada. Forest Ecology and Management 134: 271-379.

Walters, C. 1986. Adaptive management of renewable resources. Macmillan, New York, NY. 